\title{
COARTAÇÕES E ALFORRIAS NAS MINAS GERAIS DO SÉCULO XVIII: AS POSSIBILIDADES DE LIBERTAÇÃO ESCRAVA NO PRINCIPAL CENTRO COLONIAL
}

\author{
Eduardo França Paiva \\ Professor das Faculdades Integradas Newton Paiva - BH
}

\begin{abstract}
RESUMO: Entre as várias formas de alforria existentes nas Minas Gerais do século XVIII, uma merece ser destacada: a coartação. Tratava-se, grosso modo, do pagamento parcelado da manumissão, podendo o coartado se ausentar do domínio senhorial durante anos seguidos. Este texto pretende, então, informar sobre essa prática recorrente nas Minas do Setecentos, mas muito pouco conhecida pela historiografia brasileira sobre escravidāo.

ABSTRACT: Among the various kinds of alforria in Minas Gerais during the eighteenth century, one should be highlighted: the coartaçäo. It consisted of parcelled payments, granting the absence of the coartado from the landlord's domain during subsequent years. This paper, thus, discusses this common practice in the Minas Gerais of the 1700s, but vaguely known to the Brazilian historiography on slavery.
\end{abstract}

PALAVRAS-CHAVE: Escravismo, Minas Gerais, Alforria, Coartação, Século XVIII.

KEY-WORDS: Slavery, Minas Gerais, Alforria, Coartação, Eighteenth Century.

Desde o início do século XVIII existiu uma expressiva população forra em Minas Gerais. A sociedade e a economia engendradas na regiāo tornaram-na o principal centro colonial e imprimiram singularidades muito propícias às manumissōes. $O$ extenso território mineiro experimentou rápida e descentralizada urbanização; a economia diversificou-se já nas primeiras décadas do Setecentos, impondo um padrão monetarizado mesmo entre as mais ordinárias relações de troca; enormes levas de aventureiros fixaram-se nas Minas e decretaram a entrada frenética de escravos africa- nos e crioulos; nas dezenas de pequenos e grandes núcleos urbanos um grande número de senhores possuía plantéis de escravos pequenos (quatro a cinco cativos $\mathrm{em}$ média); proprietários, muitos deles, viviam e trabalhavam lado a lado com seus escravos na mineraçāo, na agropecuária, no comércio e nos serviços de oficiais mecânicos. Tudo levava à diferenciação entre os quadros mineiro e do nordeste açucareiro. Tudo favorecia a flexibilização das relaçōes escravistas; os acordos cotidianos entre proprietários e propriedades; a atuação mais autônoma dos es- 
cravos nas economias locais; a formaçāo de pecúlio por parte dos cativos e a virtualidade da libertação.

De fato, essas condiçōes logo ensejaram a formação do maior grupo de libertos da Colônia (na segunda metade do século XVIII, os forros tornaram-se ainda mais numerosos). Porém, os ex-escravos e seus descendentes passaram a incomodar as autoridades metropolitanas, que viam a constante ampliação do grupo como uma ameaça à ordem escravista e à sólida dominação branca. Era preciso controlar o movimento de manumissōes sem que tal atitude provocasse reaçōes violentas da população negra. Em 1732, o rei português $D$. Joāo $V$, através do Conselho Ultramarino, ordenou ao governador da Capitania das Minas, o Conde das Galvcas, que informasse sobre os inconvenientes "de haver negros forros nessa Capitania e sc há freqüência $\mathrm{cm}$ se concedercm alforrias ou de se libertarem os mesmos escravos"'. Alguns meses mais tarde o Conde enviou uma resposta bastante clucidativa:

$O$ que se me oferece dizer a Vossa Majestade em ordem aos negros forros é que estes ordinariamente são atrevidos, mas no mesmo tempo trabalham todos nas lavras do ouro, nas dos diamantes, nas roças e comumente faíscam para si de que se segue a Vossa Majestade a utilidade de seus quintos, que seriam menos se eles nāo minerassem, o número deles como os não distingue a cor nem o serviço dos mais escravos nāo é fácil o saber, porque não houve até agora quem o examinasse, quanto a serem frequicntes as alforrias, não há dúviđa que muitas se fazem umas por gratidāo de seus mesmos senhores, por algum serviço que deles recebem e outras com o dinheiro que ajuntam os mesmos negros, mas sempre se fazem estes contratos por interpostas pessoas porque pela sua mão não scria fácil o conseguirem, porque os senhores lhe tomariam o dito como causa própria, não só por ser adquirido pelo escravo, mas porque certamente procedia dos furtos que the tinham fei-

1. Arquivo Público Mineiro - APM/Seçāo Colonial-SC Códice 35 - "Originais de cartas e ordens régias e avisos 1732-1734", f. 118. O grifo é meu e serve para destacar o reconhecimento, por parte da coroa, das alforrias pagas pelos próprios escravos. to: os mulatos forros são mais insolentes porque a mistura que têm de brancos os enche de tanta soberba e vaidade que fogem ao trabalho servil com que poderiam viver e vive a maior parte deles como gente ociosa que se escusa de trabalhar ${ }^{2}$.

Em resumo, as alforrias c os forros eram uma espécie de mal necessário na visão do Conde Governador. Talvez, ele não tenha tido a coragem de escrever que o costume encontrava-se arraigado c era irreversívcl em Minas.

Em 1733, a coroa demonstrou, novamentc, a sua preocupaçāo com os forros mineiros. Uma nova ordem real insistia na apuração, "com toda cautela e segredo", do número de libertos. O Conde respondeu, rapidamente, que havia ordenado aos oficiais de milícia, assistentes nas freguesias, que listassem todos os libertos e suas respectivas ocupaçōes, mas que a maior parte das relações não havia chegado às suas māos, dadas as dificuldades impostas pela "largueza e vastidāo deste país". Enviava, contudo, as listas disponíveis e observava scr possivel, através delas, "fazer um cômputo prudencial dos que poderão haver nestas Minas"3.

Incomodava à Coroa, além do grande número de libertos, uma certa ascensão econômica alcançada por boa parte deles, iniciada, em muitos casos, ainda em cativeiro. Foi assim, através de pecúlio formado por escravos e cscravas, que muitos conseguiram tornar-se libertos; csses negros e negras pagaram por suas manumissōes. É claro que existiam outras formas de alforria pelas quais o cativo nāo pagava, quero dizer, pelo menos nāo com dinheiro. Essa "gratuidade" acabava sendo compensada com árduo trabalho, humilhaçōes e discriminação. Neste caso incluem-se as libertações concedidas como prêmio para delatores de irregularidades e para os que encontrassem grandes diamantes. Incluem-se, também,

2. APM/SC - Códice 35, op. cit., f.118v.

3. APM/SC - Códice 35, op. cir., f.130-130v. 
as concedidas em testamento, pelos "bons serviços prestados", por "caridade", por "afeto" e até por "gratidão"; para o testador, porém, tais legados facilitavam o seu ingresso no reino celeste. Ainda existiam as alforrias patrocinadas por pais, padrinhos, parentes, cônjuges e outros protetores, além das condicionais, que obrigavam o escravo de um testador, por exemplo, a servir outras pessoas durante anos antes de receber a carta de liberdade. Mas a maioria das manumissōes $\mathrm{cm}$ Minas talvez tenha sido paga pelos próprios escravos, dando o valor de uma única vez ou lançando māo da coartação, ou seja, do pagamento parcelado da alforria.

Resultados de acordos diretos entre as partes envolvidas, as coartações foram muito comuns na $\mathrm{Ca}$ pitania e, provavelmente, $\mathrm{cm}$ outras áreas mais urbanizadas da Colônia, como Rccife, Olinda, Salvador e Rio de Janciro. Não obstante seu uso recorrente, a prática é quase desconhecida pela historiografia brasileira sobre escravidāo, com exceção de alguns poucos cstudos (LEWKOWICZ, 1989, pp. 101-114; PAIVA, 1989; PAIVA, 1993, pp. 97-109; PAIVA, 1994, pp. 67-77; RAMOS, 1972; SCHWARTZ, 1988, p. 214). Tratava-se, pois, de uma autocompra regida por um acordo verbal estabelecido entre senhor e escravo ou, como em muitos casos, por um documento denominado Carta de Corte, assinada pelo proprietário, mas nāo registrada em cartório, pelo menos costumeiramente. Na carta, as bases do acordo eram explicitadas, como o valor acertado, a periodicidade dos pagamentos, a delimitação da região por onde o coartado poderia andar à procura de trabalho e as penas a serem aplicadas caso o acordo nāo fosse rigorosamente cumprido pelo futuro liberto (seria reconduzido ao cativeiro e os pagamentos já efetuados seriam considerados jornais devidos). Ele, então, poderia formar o pecúlio longe do domínio senhorial, mas deveria custear suas despesas com alimentaçāo, habitaçāo, vestimenta e saúde. Durante o período acertado, seu senhor não poderia vendê-lo, como observa Do- mingos Vieira (VIEIRA, 1873). Porém, em momento algum ele deixava de ser escravo, mesmo que se diferenciasse dos outros pelos privilégios temporários. Prova disso é que se uma coartada tivesse filhos durante esse período eles seriam considerados escravos do senhor da māe, independentemente da libertaçāo dela. Esses problemas parecem, no entanto, ter sido superados pelos cativos envolvidos. Durante o século XVIII não houve retração no número desses acordos. Ao contrário, acentuava-se com o passar dos anos.

A coartaçăo parece ter sido um bom negócio para senhores e escravos, o que explica ter se transformado num costume amplamente reconhecido e praticado, embora não fosse previsto pela legislação portuguesa (SCHWARTZ, 1988, p. 214). O acordo era selado sem qualquer participação do Estado, que era chamado a intervir apenas quando uma das partes contratantes se sentia lesada e não conseguia uma solução doméstica. Assim, muitos escravos recorreram aos governadores da Capitania, clamando por justiça e demonstrando estarem cientes de todos os seus "direitos" adquiridos. Vários receberam pareceres favoráveis". Foi o caso de Manoel Cabo Verde, que andava $\mathrm{em}$ desacordo com seu senhor no que se referia à sua libertação. Em 1769, ele fez enviar, do arraial do Ouro Branco, o seguinte requerimento ao Governador da Capitania:

Com o mais profundo respeito, chega aos ínclitos pés da inata piedade de Vossa Excelência, Manoel Cabo Verde, escravo de Manoel Dias de Souza, expondo na sua egrégia presença, que nos últimos requerimentos que o suplicante fez a Vossa Excelência sobre a liberdade que pretende se dignou Vossa Excelência mandar por seu venerando despacho que o suplicado desse três dias em cada semana o suplicante para tratar dos meios que por direito lhe competiam e sempre grato a este benefício insta o suplicante com

4. Processos desse tipo integram a coleção Secretaria de Governo-SG da Documentaçāo nāo encadernada da Capitania de Minas Gerais - DNECMG, no APM. 
a maior submissāo, recorrendo à nímia grandeza de Vossa Excelência, para que se digne livrá-lo de tela judiciária em atençāo à desigualdade que melita [sic] do suplicante para o suplicado e de que em tal disputa, além de que por meios sinistros pode ficar vencido, nāo tem o suplicante possibilidade para continuar pleito tão dilatado; e só pode conseguir o suplicante a liberdade que intenta, em preço justo, quando na conformidade do exposto o proteja a benignidade de Vossa Excelència [...] e vindo este (o vigário Manoel Afonso) com o suplicado e suplicante à presença de Vossa Excelência se poderá efetuar o fim que o suplicante solicita, que é a sua liberdade nas leis tão favorecidas tendo o suplicado mais escravos que o sirvam e nāo experimentando prejuizo algum [...] Para Vossa Excelência, pela sua exímia piedade, se digne atender o desvalimento do suplicante e impossibilidade para disputar com o dito seu senhor por meios judiciais, deferindo-lhe na presença conjuntura com o suplicado tem, no que Receberá Mercê e esmolas.

Como da vez anterior, o requerimento recebeu um parecer favorávcl. Manoel e quem escreveu o documento estavam cientes dos "direitos" reservados aos coartados e argumentavam muito bem. Note-se que até o procedimento judiciário chegou a ser sugerido no requerimento.

Havia, portanto, querclas entre senhores e coartados, mas isso não significa que o expediente costumasse ser complicado e acabasse sempre em disputa judicial. Ao contrário, era essencialmente doméstico e a maior parte dos problcmas surgidos era resolvida nessa esfera. Como as Cartas de Corte, quando elas existiam, nāo eram registradas em cartório, a maioria dos acordos foi finalizada sem maiores problemas e quase sem registro algum. São exceçóes as ligeiras mençōes em testamentos, inventários e em documentos que, por algum motivo, enfocavam o escravo que se encontrava coartado. Essas mençōes, porém, sāo excelentes indicativos da recorrência e do sucesso das coartaçōes em Minas. Concorreram definitivamente para isso as singularidades mineiras elencadas acima. 35 .

5. APM/SG - DNECMG - caixa-cx. 6, documento-doc.
A intensa circulação de ouro em pó (oitavas de ouro) e a informalidade do sistema de crédito existentes, principalmente, nos núclcos urbanos da Capitania facilitavam bastante a tarefa dos coartados. $O$ comércio ambulante era uma atividade freqüente, sobretudo, entre as coartadas. Muitas delas foram identificadas pela historiografia apenas como negras de tabuleiro, ressaltando-se a atividade com a qual sc ocupavam em detrimento da sua real condiçāo. A mesma perspectiva historiográfica incide sobre os escravos ao ganho, mas vários deles cstavam nas ruas buscando recursos para saldarem as parcelas acordadas com seus senhores. Outras atividades freqüentemente desempenhadas pelos coartados eram: a faiscação, a prestação de serviços mais especializados, como cozinhar e costurar, a plantação e a criação de animais (alguns senhores ou protetores cediam pedaços de terra), além de pedirem esmolas e de recorrerem às irmandades negras. Assim, em Santa Bárbara, perto de 1773, a coartada Anna Roza Pereira, de nação Angola, contava com "as criaçōes que tinha como eram capados, galinhas c scus saböes e seu milho plantado, que tudo isto eram efeitos para a sua liberdade" e na freguesia de Antônio Pereira, em 1787, o coartado Francisco, pardo, ocupava-se do "exercício de mineirar". Já a crioula Quitéria Maria da Conceiçāo, moradora em Vila Rica, em 1753, contava com o alfaiate pardo forro, lgnácio Nunez Machado, com quem iria se casar, para acabar de pagar as parcelas de sua coartação e, ainda, para "a sustentar e livrar do lupanar em que vive há tantos anos"*. A alternativa que sobrou ao coartado Matheos, de nação Angola, morador no arraial de Vira Copos (termo de Sabará), perto de 1796 , foi pedir esmolas, posto que era aleijado de uma māo e de um pé e havia contraído morféia (lepra) 9 .

6. APM/SG - DNECMG - cx. 8, doc. 23.

7. APM/SG - DNECMG - cx. 17, doc. 2.

8. APM/SG - DNECMG - cx. 5 , doc. 3.

9. APM/SG - DNECMG - cx. 60, doc. 21 . 
Em muitos casos o proprietário exigia do escravo um fiador, que era arranjado sem maiores dificuldades. Isso revela, aliás, uma outra característica do sistema escravista em Minas: uma rede de contatos e de conhecimentos que envolvia homens e mulheres livres, libertos e escravos, brancos, mestiços e negros e que era acionada cotidianamente. $O$ tamanho reduzido dos plantéis, a proximidade entre eles e a estreiteza das relaçōes entre proprietários e propriedades contribuíam fortemente para isso.

Quanto mais coartaçōes eram acertadas, mais difundido e arraigado se transformava o costume. É possível que desde muito jovens os escravos brasileiros fossem informados sobre a possibilidade e começasscm a armar estratégias para efetivá-la. Os africanos que chegavam adultos também se informavam e rapidamente se adaptavam à situaçāo. Todos que pensavam em se libertar tinham na coartação uma alternativa real e viável; restava entrar $\mathrm{cm}$ acordo com o senhor sobre o valor a ser pago, a forma de pagamento e o prazo para saldar a dívida. Quanto aos valores, estiveram, na média, sempre muito próximos aos praticados pelo mercado de escravos. Contudo, havia variação de acordo com o sexo, a idade, as condiçōes físicas e de saúde, a habilitação c a capacidade de trabalho, o grau de proximidade com o proprietário e, talvez, com a "qualidade" do coartado, isto é, negro, crioulo (fillho de negro e/ou crioulo nascido no Brasil) ou mestiço. Com relaçāo à forma de pagamento, acertava-se, geralmente, as parcelas semestrais ou anuais. Já o prazo usual das coartaçōes variou entre quatro e seis anos. É claro que pode ter havido muitas diferenças nesse padrāo, dependendo da regiāo $\mathrm{c}$ do período enfocados.

Houve coartações acordadas em núcleos urbanos e em áreas rurais, mas principalmente nos primeiros. Contudo, em fazendas e sítios da regiāo de Sabará csses acordos foram firmados desde as primeiras décadas do Setecentos, como é possível constatar através dos testamentos de seus moradores. Tam- bém nas vilas e arraiais mais distantes do centro da Capitania, como Paracatu, São Romão e Minas Novas cles foram comuns. O costume encontrava-se espalhado por toda a Capitania, mesmo que fosse mais intenso nos núcleos urbanos maiores. Esta característica acaba diferenciando o caso mineiro da coartación cubana, uma instituição reconhecida em lei, de grande importância naquela ilha, principalmente no século XIX. Lá, $40 \%$ dos coartados viviam, em 1871, na jurisdicción urbana de Havana. Além disso, os escravos cubanos recorriam a organismos oficiais, as sindicaturas, e a indivíduos importantes e favoráveis à abolição, os patrocinados, o que facilitava o acerto das coartaçöes com os senhores (SCOTT, 1991, pp. 31, 88, 89, 156, 179).

Existem, porém, semelhanças entre os dois casos. A coartação foi uma alternativa importante para as duas populações escravas no que se refere à conquista da libertação. Outra similaridade entre os dois casos é a tendência a ter havido um maior número de mulheres coartadas que de homens. Em 1871 as cubanas representavam quase $2 / 3$ do total de coartados (SCOTT, 1991, p. 31). Já os dados disponíveis para Minas Gerais não indicam diferença tão acentuada, mas atestam a vantagem feminina. Tomando como base 357 testamentos da Comarca do Rio das Velhas, entre 1720 e 1784 , identifiquei 278 coartaçōes. As escravas garantiram $53 \%$ do total ${ }^{10}$. Entre essas escravas estavam incluídas as que já tinham pago todas as parcelas, mas que estavam sendo citadas pelos testadores e as que estavam em processo de coartação ou estavam sendo coartadas em testamento.

10. Esses dados foram retirados de testamentos que se encontram nos seguintes arquivos e códices: APM/Câmara Municipal de Sabará - CMS, códices 20, 24, 53 e 73; Museu do Ouro de Sabará-MO/ Cartório do Primeiro Ofício - Testa. mentos-TEST, códices $1,2,4,8,11,12,13,16,19,48,49$, 50,51 e 52 . Mais informaçōes sobre o assunto podem ser encontradas em PAIVA, Eduardo França. Escravos... op. cit. capítulos III e IV. 
Muitos cativos viam o esforço de anos sendo recompensado apenas no testamento de seus senhores. As mulheres, diante desse quadro comum, parecem ter sido mais pragmáticas que os homens e, com certeza, usaram de todas as artimanhas disponiveis para induzir os proprietários a conceder benefícios a elas e aos familiares delas. $O$ mais desejado dos benefícios cra, cvidentemente, a libertaçāo e muitos senhores, ávidos de garantirem um lugar no céu, deixaram-Ihes alforias "gratuitas" e coartaçōes em seus testamentos, além dos lcgados materiais de todo tipo. Foi o que conseguiu Ignácia mina. Ela era māe de Miguel mulato, Ana crioula e Joana crioula e avó de Maria mulata, Zidoro mulato e Paula mulata, todos cativos (e descendentes?) de Antônio Ribeiro Vaz, portuguĉs, solteiro, morador em Sabará, cujo testamento foi escrito $\mathrm{cm} \mathrm{1760.} \mathrm{Dos} \mathrm{quinze} \mathrm{escravos} \mathrm{que}$ possuía, Antônio libertou esses sete c, curiosamente, nāo estendcu o benefício a outros quatro filhos $\mathrm{e}$ um neto de Ignácia, todos crioulos (talvez nāo descendessem dos testador). Em relação às alforrias, Antônio as justificava alegando bons serviços prestados e em seguida declarava:

[...] deixo as casas em que vivo aos ditos libertos para nclas morar os que quizercm e os que nelas não quizerem morar irão para onde quizerem pelo quc ordeno se não vendam [...] e os mais [bens possuídos] ordeno fiquem para os mesmos libertos e deles se sirvam [...]".

O português, Antônio Alvares Coelho, solteiro, morador na fazenda do Taquaraçu de Cima, termo da Vila de Sabará, onde escreveu seu testamento em 1772, é um outro bom exemplo. Ele coartou cinco escravos crioulos, entre eles quatro irmãos de Josefa, sua fil ha com uma escrava que já havia falecido. Antônio tinha a intenção clara de tornar menos difícil a obrigação dos coartados e, para isso, declarava:

11. APM-CMS - códice 24, f. $117 \mathrm{v}$ e 118 . Testamento de Antônio Ribeiro Vaz - Sabará 14 FEV 1760.
[...] caso queiram trabalhar e plantar na parte que me toca de minha fazenda [era ścio de seu irmão], meu testamenteiro e herdeira lhes darão terras para isso por serem crias da casa e não ser razão corter com eles, antes peço the façam todo o favor para conseguirem melhor a sua liberdade, mas querendo os mesmos fora da fazenda tratar da vida se lhes nāo impedirá correndo o tempo de cinco anos ${ }^{12}$.

No processo de conquista de seus objetivos as escravas não enfrentaram muitas dificuldades para estabelecerem intercursos sexuais com os poderosos. Incorporaram valores sociais dominantes e expressaram, real ou forjadamente, afeto, lealdade e gratidão. A habilidade nos serviços domésticos e na preparação da comida e o cuidado dispensado ao senhor e a familiarcs dele no caso de doenças também foram fórmulas usadas para sensibilizá-los. Com isso, elas receberam alforrias e coartaçôes e, em várias oportunidades, conseguiram que o benefício fosse estendido a seus filhos (que eram, muitas vezes, filhos delas com os próprios senhores).

A prescnça constante da família escrava (basicamente constituída pela mãe e os filhos) nos plantéis mineiros parece ter sido, cntāo, fator importante para que a libertaçāo fosse alcançada, através das alforrias "gratuitas" ou através das coartaçōes. Tudo isto, não há dúvidas, foram cstratégias de resistência ao sistema cscravista, desenvolvidas cotidianamente por esses autênticos agentes históricos.

Famílias escravas e processos de libertação a partir de testamentos da comarca do Rio das Velhas, Minas Gerais, entre 1720 e 1784.

\begin{tabular}{|lccc|}
\hline & Escravos & Alforriados & Coartados \\
\hline Mães Africanas & 101 & 27 & 30 \\
Mães brasileiras & 45 & 11 & 13 \\
Mães scm origem & 46 & 12 & 03 \\
identificada & & & \\
Total de Mães & 192 & 50 & 46 \\
Filhos & 218 & 100 & 20 \\
Filhas & 184 & 85 & 34 \\
Total_dc Filhos & 402 & 185 & 54 \\
\hline
\end{tabular}


Os dados dispostos no quadro acima, retirados dos mesmos testamentos acima mencionados, deixam mais clara a situação. Os cativos incluídos neste quadro representam $18,14 \%$ dos 3.274 escravos possuidos pelos testadores arrolados. Além disso, essas mães e os seus respectivos filhos e filhas somam $95 \%$ do universo de parentes mancípios resgatado nos testamentos; o restante deles constituía-se de pais, avós e avôs. Do total de mães escravas identificadas pelos testadores, $50 \%$ foram alforriadas gratuita ou condicionaimente ou foram coartadas. $E$ com relação aos descendentes delas, contando com os filhos dos senhores, $59,45 \%$ também foram beneficiados com alforrias ou coartações. Um aspecto importante, relativo a esses últimos, é que o número de forros chega a ser mais de três vezes superior ao número de coartados, enquanto que entre as mães quase não existe variaçăo.

Números também bastante sugestivos e que permitem dimensionar a importância da família escrava como estratégia de libertação são os que seguem. As 250 alforrias conquistadas pelos escravos, cujos laços de parentesco foram declarados pelos testadores, representam 56,17\% das 445 manumissōes registradas nos testamentos examinados. Proporção menor, mas näo menos importante, resulta de idêntica comparação feita entre os coartados: as 103 coartaçōes de escravos em família, representam $37,05 \%$ do total de 278 autocompras identificadas. Somadas, as alforrias e coartaçōes de escravos com laços de parentesco representam $48,82 \%$ de todos os casos existentes nos testamentos. Não é pertinente tentar explicar esses índices através, unicamente, dos intercursos se. xuais entre os senhores e suas escravas e das libertações, quase que obrigatórias, dos filhos reconhecidos, resultados dessas relaçōes. As uniōes entre se-

12. APM/CMS - códice 53, f. 86. Testamento de Antônio Alvares Coelho - Fazenda do Taquaraçu de Cima 07 MAI 1772. nhores e escravas eram freqüentes, mas nāo devem ser superestimadas. Houve uniōes dessas escravas com escravos do mesmo plantel e com cativos de outros proprietários, além de parceiros libertos e livres. A maior parte dos filhos e filhas incluídos no quadro acima é oriunda desses últimos tipos de relacionamento. No que se refere aos filhos dos senhores com suas escravas, ê preciso observar que se trata de um conjunto relativamente pequeno, embora subestimado, uma vez que nem todos os testadores reconheceram seus descendentes ilcgítimos: foram identificados 21 homens e 18 mulheres. Esses receberam suas alforrias, mesmo porque ao serem reconhecidos tornaram-se, automaticamente, herdeiros dos pais.

Uma grande parte dos filhos e filhas incluídos no quadro acima tinha māes africanas e muitos foram identificados como crioulos nos testamentos. Mais de $50 \%$ deles (mães e filhos) receberam alforrias e coartaçōes de seus proprietários, que eram, majoritariamente, homens brancos. Nesses casos, também, filhos ilegítimos não reconhecidos podem estar sendo identificados como escravos "crioulinhos", ao invés de serem listados como crianças mulatas e pardas, o que poderia evidenciar a paternidade. Mas isso não aconteceu sempre c, além do mais, o fato de existirem "mulatinhos" nos plantéis não significava que eles fossem filhos dos senhores brancos. Quando esses proprietários tencionavam nâo assumir a paternidade dos bastardos escravinhos era-lhes possível lançar mão de mecanismos eficazes, como, por exemplo, o suborno e os legados de toda monta deixados em testamento. Mas são atitudes virtuais, nem sempre passiveis de serem comprovadas. De toda forma, as manumissōes e as coartaçōes pretendidas acabaram tornando-se realidade para muitos escravos mineiros, como nos casos que seguem. O português Manoel Fernandez Aleixo, solteiro, morador em Santa Luzia, em 1762, atestava:

Declaro que minha escrava Francisca mina e sua filha Vicência crioula, quero e é minha última vontade que fiquem 
ambas forras c com efeito as hei por forras, livres e libertas como se forras nascessem do ventre de sua mãe, sem que lhes fique obrigação alguma do cativeiro e as forro pelo amor de Deus e pelos bons serviços que delas tenho recebido e quando eu em minha vida lhe não tenha passado suas Cartas de Alforria, nāo tenha dúvida meu testamenteiro em thas passar logo para tratarem de suas vidas como forras que ficam sendo ${ }^{13}$.

Já o português Antônio Carlos Moreyra de Sam Payo, soltciro, morador em Sabará, cm 1751, dizia possuir uma negra chamada Marta c um "crioulinho" cujo nome nāo é mencionado e seguia declarando

[...] que à dita negra Marta dei licença para ir para o Paracatu a tratar de sua alforria e por conta dela tenlo recebido trinta e duas oitavas de ouro por tê-la coartado, a ela e a seu filho, $\mathrm{cm}$ cento e sessenta oitavas de ouro, os quais escravos me pertencem e por esquecimento nāo fiz declaraçāo deles quando nomeei os mais e no caso que a dita negra dê o resto da quantia com que a coartei e a scu filho o meu testamenteiro the passará Carta de Alforria ${ }^{14}$.

Assim como essas escravas várias outras, em todo o século XVIII e também no século XIX, alcançaram sua libertação a partir de estratégias e de acordos desenvolvidos no dia-a-dia das relaçōes escravistas. As coartaçōes, mesmo sendo pouco registradas nos documentos coloniais, possibilitaram boa parte das manumissōes ocorridas em Minas. Eram, também, a origem de significativa parcela dos 123000 libertos moradores na Capitania, em 1786 (KLEIN, 1987, p. 85).

13. APM/CMS - códice 24 , f. 96v. Testamento de Manoel Fernandez Aleixo - Santa Luzia 22 MAl 1762.

14. APM/CMS - códice 20, f. 85v. Testamento de Antonio Carlos Moreyra de Sam Payo - Sabará 10 FEV 1751.
Para que a enorme população forra mineira, talvez, uma das maiores em todo o Novo Mundo escravista, se formasse foi essencial a ocorrência daquele conjunto de características já identificado e chamado de singular. Vale a pena relembrar que a precoce diversificação da economia; a rápida e extensa urbanizaçāo; a circulação intensa de ouro em pó (oitavas de ouro); a construção de um informal e abrangente sistema de crédito; a grande populaçāo escrava dividida em pequenos plantéis $\mathrm{e}$ a conseqüente cstreiteza das relaçōes entre proprietários e propriedades em sentido amplo -, tudo isto acabou favorecendo, e muito, a possibilidade de formação de pecúlio entre os escravos. Não foram incomuns, por exemplo, os escravos proprietários de outros escravos. E com as oitavas de ouro acumuladas através de inúmeras atividadcs paralelas às obrigaçōes do cativeiro esses escravos puderam pagar suas manumissões de uma única vez ou iniciar um processo de pagamento parcclado, isto é, a coartação.

Deve-sc observar, ainda, sobre a possibilidade de as coartaçōes e a libertação no geral terem sido vistas diferentemente por senhores e escravos. Para os primeiros, é provávcl que elas tenham significado uma espécie de "válvula de escape" social, isto é, eram vistas como concessões feitas a uma razoável parcela daquela massa de escravos, o que acabava por intimidar virtuais reaçōes violentas, individuais e coletivas. Ao mesmo tempo, representavam para esses senhores um eficaz mecanismo de controle que obrigava a populaçāo negra a incorporar, reproduzir e legitimar valores básicos daquela sociedade escravista. Já para os mancípios, tratava-se da conquista do mais valioso dos bens: a libertação. Para conseguí-la, tudo valia a pena, até mesmo teatralizar submissão e passividade. 


\section{Bibliografia}

KLEIN, Herbert S. A Escravidāo Africana: Amćrica Latina c Caribc. São Paulo, Brasiliense, 1987.

LEWKOWICZ, Ida. "Herança e Relaçōes Familiares: os Pretos Forros nas Minas Gerais do Século XVIII". Revista Brasilcira dc História. São Paulo, ANPUH/Marco Zero, n. 17, 1989, pp. 101-114.

PAIVA, Eduardo França. Coartaçōes, Alforrias c Escravidão Urbana na Capitania de Minas Gerais. Monografia de Bacharelado apresentada ao Depto. de História da UFMG, Belo Horizonte, 1989.

Escravos c Libertos nas Minas Gcrais do Século XVIII: Estrategias de Resistência Através dos Testamentos. Dissertaçāo de Mestrado apresentada ao Depto. de História da UFMG, Belo Horizonte, 1993.

"Mulheres, Famílias e Resistência Escrava nas
Minas Gerais do Século XVIIl". Varia Historia, n. 13. Belo Horizonte, UFMG, 1994.

RAMOS, Donald. A Social History os Ouro Preto - Stresses of Dynamic Urbanization in Colonial Brazil -1695. 1726. The University of Florida-PhD, 1972 ,

SCHWARTZ, Stuart B. Scgredos Internos: Engenhos e Escravos na Sociedade Colonial - 1550-1835. (trad.) Sāo - Paulo, Cia. das Letras/CNPq, 1988.

SCOTT, Rebecca J. Emancipação Escrava cm Cuba: a Transiçáo para o Trabalho Livre 1860.1899. (trad.) Rio de Janeiro/Campinas, Paz e Terra/Editora da UNICAMP, 1991.

VIEIRA, Domingos. Grandc Diccionario Português. Porto, Editores Ernesto Chardron e Bartholomeu H. de Morais, 1873

Endereço do Autor: Avenida Costa do Marfim, 35 apto. 102 • CEP 30575-000 - Belo Horizonte-MG - Brasil • FAX 55 (031) $378-1254$ 